transgenes capable of interfering with $X$. fastidiosa infection of grapevine or the mechanisms on which they might operate. Infecting $X$. fastidiosa bacterial cells reside not in the living cells of the plant, where a transgene product normally would accumulate, but in the xylem, the array of dead cells that form the vascular elements responsible for conducting water and minerals from the roots into the aerial parts of the plant. Responding to this challenge, researchers not only identified various genetic elements that encode molecules that restrain the accumulation and/or spread of $X$. fastidiosa but also elements that deliver these molecules to the xylem. Importantly, several of the molecules were shown to cross graft unions and to confer, as a transgenic rootstock, protection to a grafted nontransgenic scion. Rootstock-conferred resistance has obvious versatility: Varietal scions now in use could be grafted onto the transgenic rootstock line and be at least partially protected against $X$. fastidiosa.

The transformed lines that have been examined closely are indistinguishable from the untransformed lines from which they were derived (Dandekar et al. 2011; Lindow et al. 2014), suggesting that the vines have the quality and horticultural traits of the untransformed lines. This result is expected because the transformation process introduces only a minute change in the plant genome. In commercialization, combinations of several transgenes acting through distinct biochemical mechanisms of action likely would be introduced into a grapevine line to obtain at least additive resistance effects and to greatly reduce the chance that a variant $X$. fastidiosa would be able to overcome resistance. The following paragraphs summarize five mechanistically diverse and clever experimental approaches for developing transgenic resistance to $X$. fastidiosa in grapevines.

Fusion of two proteins. One straightforward approach to reducing the titer of $X$. fastidiosa in grapevine xylem is to discover or develop a protein capable of killing or preventing the increase of $X$. fastidiosa cells and then to deliver that protein to the xylem. A research group headed by Abhaya Dandekar at UC Davis and including Goutam Gupta of Los Alamos National Laboratory conceived the approach of fusing two proteins, each with some activity against $X$. fastidiosa, into a single, xylem-targeted protein. One protein of the fusion pair binds to a specific protein that is abundant on the surface of the $X$. fastidiosa cell. The other protein breaches the $X$. fastidiosa cell membrane, thereby killing the bacterial cell. Both proteins killed X. fastidiosa cells

\title{
Coordinated response to PD involves growers, scientists and government
}

$$
\text { he }
$$

he academic and government research on GWSS and PD

received support from the state's viticulture and enology industries and even local government before and during the Temecula Valley outbreak. Industry organizations partnering with CDFA and UC Division of Agriculture and Natural Resources (UC ANR) in these efforts included the American Vineyard Foundation, the California Table Grape Commission, the California Raisin Board and the California Rootstock Commission. UC ANR and CDFA provided

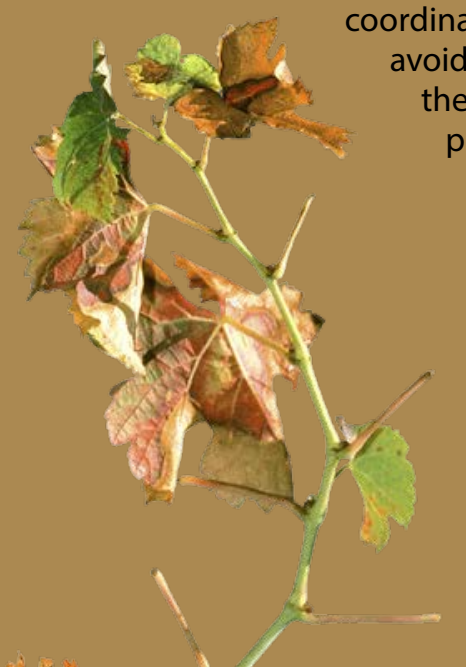
ordination to prioritize research, void duplication and maximize the collective benefits of the programs. Since 1999, USDA has provided about $75 \%$ of the funding for PD control and research, and the state of California, industry and UC have provided the rest. California legislation initiated a statewide assessment on wine grapes to support research and related activities, raising about $\$ 46$ million to date (Tumber et al. 2014; Wiggins 2001). The timeline here highlights some of the key events in the efforts to contain and find solutions to the PD outbreak in California.

\section{6}

UC ANR forms Viticulture Consortium (VC), funded by a grant from USDA Cooperative State Research, Education, and Extension Service (USDA CSREES, now USDA NIFA, National Institute of Food and Agriculture).

Report of GWSS establishment in Southern California is published.

1997

Industry-matched state funds initiate the California Competitive Grant Program for Research in Viticulture and Enology (CCGPRVE).

1998

Search for biological control agents for GWSS begins. 1999

Temecula Valley vineyards show severe damage from PD; GWSS is recognized as the vector.

Riverside County declares emergency; the county and city of Temecula each contribute $\$ 125,000$ for research.

UC appoints Pierce's Disease Research and Emergency Response Task Force to identify strategies for combating PD.

CDFA appoints task force with members from UC, California State University, CDFA, county agricultural commissioners, USDA and industry to identify PD/GWSS research priorities.

CA Assembly Bill 1232 provides $\$ 2.25$ million over 3 years to be matched by $\$ 0.75$ million in industry funds for PD/GWSS research; the CDFA competitive grants program is funded. 
in culture, but the fusion protein was significantly more potent than either protein component alone. Grapevines expressing the fusion protein showed significant protection against PD (Dandekar, Gouran et al. 2012).

HxfA protein. Bruce Kirkpatrick's laboratory at UC Davis identified a protein of X. fastidiosa, HxfA, which, when inactivated, surprisingly led to increased virulence of the bacterium (Guilhabert and Kirkpatrick 2005). This result suggests that, when active, HxfA suppresses virulence. Perhaps a grapevine line that produces HxfA could reduce PD severity by decreasing the virulence of infecting $X$. fastidiosa, and infecting $X$. fastidiosa would be less successful at inducing PD than in unaltered vines. Grapevine plants producing full-length or truncated versions of HxfA were constructed. The genes were designed to cause the HxfA protein to be secreted into the xylem, where infecting $X$. fastidiosa cells colonize the vine. Greenhouse-grown plants were found to have reduced disease symptoms compared to unaltered grapevines when inoculated with a high dose of $X$. fastidiosa (Kirkpatrick et al. 2012).

XfDSF, pathogen confusion. Steven

Lindow and his research associates at UC Berkeley intensely investigated intercellular communication of $X$. fastidiosa and applied their findings to suppress the spread of the bacterium in the plant using a phenomenon they refer to as pathogen confusion. X. fastidiosa secretes a specific 14-carbon fatty acid and possibly other similar molecules as diffusible signal factors (XfDSF). As X. fastidiosa populations grow, the concentration of XfDSF around the cells increases. Compared to the unaltered bacterium, X. fastidiosa mutants that fail to produce XfDSF spread more readily in the plant, whereas spread of mutants that overproduce XfDSF is severely restricted (Chatterjee et al. 2008).

Transfer of a gene whose product catalyzes XfDSF synthesis should result in accumulation of XfDSF even in the absence of X. fastidiosa and, after inoculation with $X$. fastidiosa, should constrain movement and accumulation of $X$. fastidiosa and reduce PD symptom extent and intensity. These expected results have been observed (Lindow et al. 2012, 2014).

Programmed cell death. The characteristic scorching symptoms of PD were shown by the laboratory of David Gilchrist at UC Davis to be an example of the phenomenon known as genetically programmed cell death, where the symptoms resulted from a reaction of the plant to the presence of a bacterium (X. fastidi$o s a)$ rather than directly to an action of that bacterium (Gilchrist et al. 2007). This
2000

UC is awarded USDA CSREES grant of $\$ 2$ million to establish a competitive grants program for PD/GWSS research; annual funding was renewed eight times.

UC establishes Pierce's Disease Competitive Grants Program.

CA Senate Bill 671 provides funds for a coordinated statewide effort against PD/GWSS.

Federal government declares emergency and provides $\$ 22.3$ million for GWSS containment and PD research.

First GWSS infestation is found outside the generally infested Southern California area, in Contra Costa County; eradication efforts begin.

CDFA adopts emergency regulations to prevent spread of GWSS on shipments of nursery stock, bulk grapes and (later) citrus.

2001

CA Assembly Bill 1394 creates the Pierce's Disease and GlassyWinged Sharpshooter Board and an assessment on wine grapes to fund PD/GWSS research and related activities; this assessment raised \$46 million through February 2014.

First area-wide management program begins in Kern County, testing methods for controlling PD and GWSS in large and diverse agricultural areas.

First annual PD/GWSS research symposium takes place.

\section{2}

GWSS infestation found in Contra Costa County in 2000 is declared eradicated, marking the first successful eradication of a localized GWSS infestation.

\section{4}

CDFA and UC competitive PD/GWSS research programs combine their proposal review processes.

CDFA-requested report "California Agricultural Research Priorities: Pierce's Disease" is published by National Research Council of the National Academies.

Number of GWSS biological control agents released in California since 1999 exceeds 1 million.

\section{5}

California wine grape growers vote to continue statewide PD/ GWSS wine grape assessment.

\section{8}

Nursery Stock Approved Treatment Protocol established to reduce need for GWSS inspections.

\section{0}

California wine grape growers vote again to continue statewide PD/GWSS wine grape assessment, with option to support research and outreach on other wine grape pests and diseases.

2011

Last CCGPRVE-supported project completed, and the program ends.

\section{3}

Last projects funded by USDA-UC and VC are completed; these programs end.

Industry-funded CDFA competitive grants program continues, with its proposal review process now conducted under UC ANR's Unified Grant Management for Viticulture and Enology. CA 